\title{
Effectiveness of Video Modeling in Teaching Computer Skills to Students with Intellectual Disabilities
}

\author{
Naime Güneş Özler ${ }^{1} \&$ Gönül Akçamete ${ }^{2}$ \\ ${ }^{1}$ Child Protection and Care Services, Hitit University, Çorum, Turkey \\ ${ }^{2}$ Special Education, Near East University, Lefkoşa, Turkish Republic of Northern Cyprus, Turkey \\ Correspondence: Naime Güneş Özler, Child Protection and Care Services, Hitit University, Vocational School of \\ Health Services, Vocational Schools Campus Gazi Street No: 99 Çorum, Turkey.
}

Received: August 23, 2021

Accepted: October 22, $2021 \quad$ Online Published: November 11, 2021

doi:10.5539/jel.v11n1p40

URL: https://doi.org/10.5539/jel.v11n1p40

\begin{abstract}
The purpose of this study is to determine whether video modeling is effective in teaching computer skills to students with intellectual disabilities. The study was designed with the multiple probe design across subjects, one of the single-subject research designs. The study was conducted with three female students with intellectual disabilities, who were 17-19 years old. Graphical analysis was used to analyze the data. The results show that video modeling was effective for them to acquire and retain skills for preparing a résumé, printing it out, and emailing it. However, the students had difficulties generalizing some of the skills on different computers and printers. It can be said that the reason for this originates from different designs of technological tools. In line with this, it is thought that removing the accessibility barrier in technological equipment will increase availability. The video modeling motivated students to learn computer skills. The participants reported that they could use these skills to do homework, apply for a job, and communicate with friends.
\end{abstract}

Keywords: intellectual disability, computer skills, video modeling, universal technological design

\section{Introduction}

The use of technology for education and work is an inevitable part of our daily lives. A long list of technological devices makes our lives easier and computer skills are especially important in health, business, communication, correspondence, commerce, education, entertainment, and industry (Burgstahler, 2003; Wehmeyer et al., 2004). As computers are increasingly integrated in our daily lives, it is important for individuals with intellectual disabilities to have computer skills. These skills make it possible for them participate and contribute at home, school, and work, interact with their peers, and take advantage of opportunities. Greater computer skills increase job qualifications, self-confidence, and motivation (Edrishinha et al., 2011; Kagohara, 2011; Jerome, Frantino, \& Sturney, 2007; Schimizu \& McDonough, 2006; Wehmeyer et al., 2004). This helps them be more accepted by society and be more independent. This leads to greater success in higher education, employment, and interpersonal communication with other adults (Burgstahler, 2003; Edrishinha, O'Reilly, Choi, Sigafoos, \& Lancioni, 2011; Kagohara, 2011; Jerome et al., 2007; Wehmeyer et al., 2004).

The legal regulations in the USA and Europe are aware of this; for example, it is part of the Individuals with Disabilities Education Act (1997) in the USA (Burgstahler, 2003). Likewise, the 2010-2020 European Disability Strategy aims to ensure that individuals with special needs have access to technology and all other support and services on an equal basis and that technology is part of their curricula and future lives (European Comission, 2010). Acquiring computer skills increases the motivation of individuals with intellectual disabilities as they transition from school to employment. This makes them more attractive to potential employers, who often expect employees to have these skills (Baran \& Cavkaytar, 2007; Burgstahler, 2003; Güneş \& Akçamete, 2014; Lamb, 2003; Luecking, 2003; Ju, Zhang, \& Pacha, 2012; Stodden, Conway, \& Chang, 2003; Wehmeyer et al., 2004).

However, there are many obstacles to acquiring computer skills by individuals with intellectual disabilities, which can be both environmental factors and individua; they are, summarized here from Burgstahler (2003) and Wehmeyer et al. (2004). Environmental factors include: a) their families regarding computer skills as a waste of time, b) parents' concerns that their children will be cheated or exposed to abuse when they use computers, c) parents not having sufficient knowledge and equipment to teach computer skills to their children, d) low incomes, 
e) teachers not knowing how to teach these skills, and f) the lack of adequate equipment in schools. Individuals with intellectual disabilities may experience difficulties in performing cognitive and motor skills. Cognitive disabilities in visual perception and slow learning are extra challenges, especially for complex skills. Using a mouse and a keyboard requires fine motor control, which may not be well developed.

There are studies on teaching computer skills to individuals with intellectual disabilities. Shicmizu and McDonough (2006) implemented an effective training program to teach the skill of using a mouse to three pre-school students with special needs. Jerome et al. (2007) taught three students with special needs to use the internet, specifically sites the students were interested in. They used the teaching methods of backward chaining and gradual prompt fading. The participants were able to generalize the skills on the same computer with a different orientation. Shih (2013) developed and taught four participants to use a pointing assistance program for people who could not use a normal mouse. Chiak, McMahon, Smith, Wright and Gibbons (2015) used the least-to-most prompt method to teach four individuals with intellectual disabilities to send e-mails on desktop, laptop, and tablet computers. Using video modeling, Edrishinha et al. (2011) taught four students with special needs to take and print photographs using a digital camera, a laptop, and a printer. Zisimipoulos, Sigafoos and Kountramanos (2011) taught three students to download images for a history lesson from the internet using video modeling and the constant time delay teaching method.

Overall, there are few studies on teaching skills that can be used to translation from school to work, as shown by a meta-analysis by Domianidou, Arthur-Kelley, Lyons, and Wehmeyer (2019). Other studies focused on using a mouse and sending emails (Chiak et al., 2015; Shih, Chang, \& Shih, 2009, Shih et al., 2010; Shih, Li, Shih, Lin, \& Lo, 2010). In line with the 2010-2020 European Disability Strategy, it is important teach individuals with special needs to use technology and transfer it to their future lives. We suggest that video modeling is an effective method.

Like everyone, people with intellectual disabilities respond better to visual stimuli and benefit more from teaching with visual materials (Zirpoli \& Melloy, 1997). Those with intellectual disabilities have may difficulties with paying attention and retaining information, so visual methods are especially appropriate (Kellems \& Morningstar, 2012). Video modeling is a repeatable and can result in fast and permanent learning since it increases success and motivation, which has been observed for teaching daily life and vocational skills (Ashton, 2003; Sani-Bozkurt, 2017). This study aims to examine the effectiveness of computer-assisted video modeling in teaching computer skills to students with intellectual disabilities. We address the following questions.

1) Is video modeling effective in teaching computer skills to students with intellectual disabilities?

2) Do students retain these skills?

3) Is the method effective with different people, settings, and equipment?

4) What are the views of the students, their families, and teachers who participated in the study?

\section{Methods}

\subsection{Participants}

To participate, students had to have the following skills and capabilities:

1) pay attention to visual stimuli for at least $15 \mathrm{~min}$,

2) watch and follow three-step verbal instructions,

3) participate in an activity for at least $20 \mathrm{~min}$,

4) have good hand-eye coordination,

5) perform gross and fine motor skills,

6) have good enough eyesight to watch videos,

7) receptive and expressive language skills, and

8) basic literacy skills.

Based on observations of these skills by families and researchers, all three participants met had these requirements. Permission was obtained from the students' families. The students all have mild intellectual disabilities and did not have computer skills before the study. They are all eleventh-graders at the vocational high school and attend a special education class where they learn to make clothes. One other student began but did not finish the study.

Gaye and Sinem are 17 years old; Betül is 19 years old (pseudonyms are used here). They can independently meet their daily and self-care needs, understand and apply verbal instructions, express themselves in four-to-six-word sentences, and have good gross and fine motor skills. They can add and subtract, have basic literacy skills, and can 
answer questions about written texts. Their technology skills include making calls, taking photographs, and listening to music their mobile phones. In their workshop class, they know how to use the sewing machines, irons, and overlock machines.

\subsection{Procedures}

The probe, teaching, and maintenance sessions of the study were carried out in the teacher's room in the clothing workshop the students attend. The generalization sessions were conducted in the officer's room of the same school outside of working hours. Videos were filmed with mobile phones. Videos of each session were copied to the laptop and watched there. In the generalization sessions of the study, they used a computer monitor, case, printer, wireless keyboard, and wireless mouse.

\subsubsection{Intervention Processes}

The intervention comprised the pilot study, pre-teaching probe to collect baseline data, video modeling teaching sessions, daily and multi probe sessions, maintenance, and generalization sessions.

The pilot study was carried out to assess possible problems. Apart from the three participants, the pilot study also included a fourth student who had a better understanding and comprehending, Demet. She is 19 years old and in the same class as the other students and has the same skills. The pilot study was conducted to perpare a résumé in the program Microsoft Word. Close-up videos were made to help her with difficult points. She had difficulty remembering all the elements of the résumé, so a printed paper template was kept on the table next to her. When the pilot study was repeated after arrangements, problems disappeared and the intervention was initiated.

At least three consecutive sessions were conducted for all three skills until stable data were obtained. The single-opportunity method was used to collect data on the participants' performance. The following steps were followed in the probe session:

1) The researcher presented the prompt to attract the student's attention. (e.g., "Today, we will work with you on preparing a résumé in the program Word on the computer, are you ready?").

2) The target skill was presented.

3) The participant's correct behaviors were recorded and if the participant responded incorrectly or did not respond within five seconds, the study was ended.

4) The student's participation were verbally reinforced

5) The student's incorrect responses or non-reactions were recorded.

The following steps were followed in video modelling teaching session:

1) Before starting, the implementer brought the participant to the study setting, introduced the equipment, and explained the task (e.g., "We will work on the skill of preparing a résumé in Word. Here, there is a computer screen, a computer case, a keyboard...").

2) The implementer presented a stimulus to attract attention (e.g., "Shall we watch a video together?").

3) After the participant agreed, the implementer and the student sat at the laptop and opened the video.

4) The implementer drew the student's attention to the video (e.g., "Watch the video carefully").

5) After the clip ended, the implementer verbally reinforced the subject for paying attention to the video.

6) The implementer made an instruction and waited for a response (e.g., "Now it's your turn to prepare a résumé like in the video!"). The student was reminded that the paper template was available.

7) As the participant made the correct steps, she was verbally reinforced and this was recorded.

8) If the participant did not respond after five second or gave an incorrect response, the implementer asked the student to watch the video again to correct mistakes.

9) The video was repeated by no other instructions were provided. The implementer reinforced the subject for paying attention to the video.

10) The implementer repeated the skill instruction and waited for a response. Correct responses were reinforced verbally.

11) If the participant did not respond after five second or gave an incorrect response, the session was ended (e.g., "We are stopping now, today's session is over. You participated very well").

The instructional video was only shown twice. The same process was followed in the other sessions. The students' 
performance was evaluated in all sessions after the initial probe. All sessions were held in the same way. After the target skill was acquired and stable data were obtained from three consecutive sessions, a session was held with all skills in a multiple-skill session.

Skill maintenance sessions were done 12, 21, and 32 days after the target skill was acquired. Generalization sessions were held in the officer's room with different brands of equipment. The data from the generalization sessions were evaluated with the pretest posttest application. Before starting the intervention process, probe data for target skills were collected.

\subsection{Data Collection and Analysis}

Three types of data were collected in the study, effectiveness, social validity, and reliability. The first two were collected by the implementer.

\subsubsection{Effectiveness Data}

The effectiveness data are shown with line and column charts. The social validity data were evaluated qualitatively. These data were collected by a special education teacher with a Master's degree. Study data were collected and analyzed by examining the video recordings taken during the sessions. Social validity data were collected from the participants, their families, and teachers after at least $30 \%$ of the sessions. They were asked the questions such as:

"In your opinion, what contributions have this study made?"

"What has this study provided you?"

"What changes have you observed in your student/child after this study?"

Answers were evaluated with content analysis based on interobserver agreement and procedural adherence.

\subsubsection{Interobserver Agreement Data}

Interobserver agreement data were collected by a teacher with a Master's degree in special education. The observer and the implementer independently examined videos of randomly selected sessions and scored them. The interobserver reliability coefficient was calculated using the formula "Agreement / (Disagreement + Agreement) $\times$ 100."

\subsubsection{Procedural Adherence Data}

The observer randomly selected procedural adherence data and evaluated data for the teaching and probe sessions. During the study, procedural adherence data were collected with probe and video modeling teaching procedural adherence forms. For video modeling teaching sessions, data were collected regarding whether the implementer appropriately exhibited the behaviors of:

1) preparing equipment, preparing the video footage,

2) paying attention,

3) watching the video footage and reinforcing the watching behavior,

4) presenting skill instructions,

5) responding appropriately to the reactions,

6) watching the video demonstration for the second time,

7) repeating the intervention process, and

8 ) reinforcing the participant's behavior.

For the probe sessions in the intervention process, data were collected regarding whether the implementer exhibited the behaviors:

1) preparing equipment,

2) paying attention,

3) presenting skill instructions,

4) responding appropriately to the reactions, and

5) reinforcing the participant's behavior.

Procedural adherence data were estimated with the formula "Observed Implementer Behavior / Planned Implementer Behavior × 100." 


\subsection{Research Design}

This study tracked learning across multiple sessions to investigate the effectiveness of video modeling in teaching computer skills to students with intellectual disabilities. This study tested evaluated effectiveness with multiple variables for three skills (Tekin-İftar \& Kırcaali-İftar, 2013). To make the results more reliable, we asked participants not to do any addition learning on their own or with others.

The independent variable of the study is teaching with video modeling. Videos of an adult performing the skills were recorded with a mobile phone, transferred to a laptop, and played on the laptop.

The dependent variables are the students' skills in preparing a résumé in the program Word, using Gmail to send an email with the résumé attached, and printing the résumé. These skills were selected because they will be important when students apply for jobs after they finish school. To measure the level of skill acquisition, tasks were divided into steps for the three main tasks, which had 66, 29, and 12 steps, respectively. A researcher and a special education teacher independently tracked each student's ability to perform each step. An email account was created for all three students and they were provided with the login information as well as the address to send the résumé to.

\section{Findings}

\subsection{Reliability}

The interobserver agreement data of the study are given in Table 1. In the intervention and probe sessions of the study, procedural adherence data for Gaye, Sinem, and Betül were $100 \%$.

Table 1. Interobserver agreement data for Gaye's, Betül's, and Sinem's baseline, intervention for the daily probe, multiple probe, maintenance, and generalization sessions

\begin{tabular}{lllllll}
\hline Subjects & Baseline & Intervention & Daily probe & Multiple probe & Maintenance & Generalization \\
\hline Gaye & $100 \%$ & $97.65 \%$ & $100 \%$ & $100 \%$ & $100 \%$ & $100 \%$ \\
Betül & $100 \%$ & $100 \%$ & $93.91 \%$ & $100 \%$ & $100 \%$ & $100 \%$ \\
Sinem & $100 \%$ & $100 \%$ & $100 \%$ & $100 \%$ & $100 \%$ & $100 \%$ \\
\hline
\end{tabular}

\subsection{Effectiveness}

Effectiveness data were collected for the following sessions: baseline, intervention, multiple probe, maintenance, and generalization. Figure 1 shows Gaye's baseline data at a level of $4.5 \%$ steps in preparing a résumé in Word. She completed all 66 skill steps independently at the end of nine sessions. For printing and emailing, Gaye began with $0 \%$ of the necessary steps but after six sessions, completed these tasks independently. She maintained all three of the skills she had acquired 12,21, and 32 days after the study. Figure 2 shows the findings of the generalization session of Gaye's skills of preparing a résumé in the Word program, printing, and sending an e-mail. She generalized all the steps for preparing a résumé and emailing across different settings, equipment, and people. However, she only generalized $66 \%$ of the steps for printing, since the printer had a different a power button and paper drawer. 


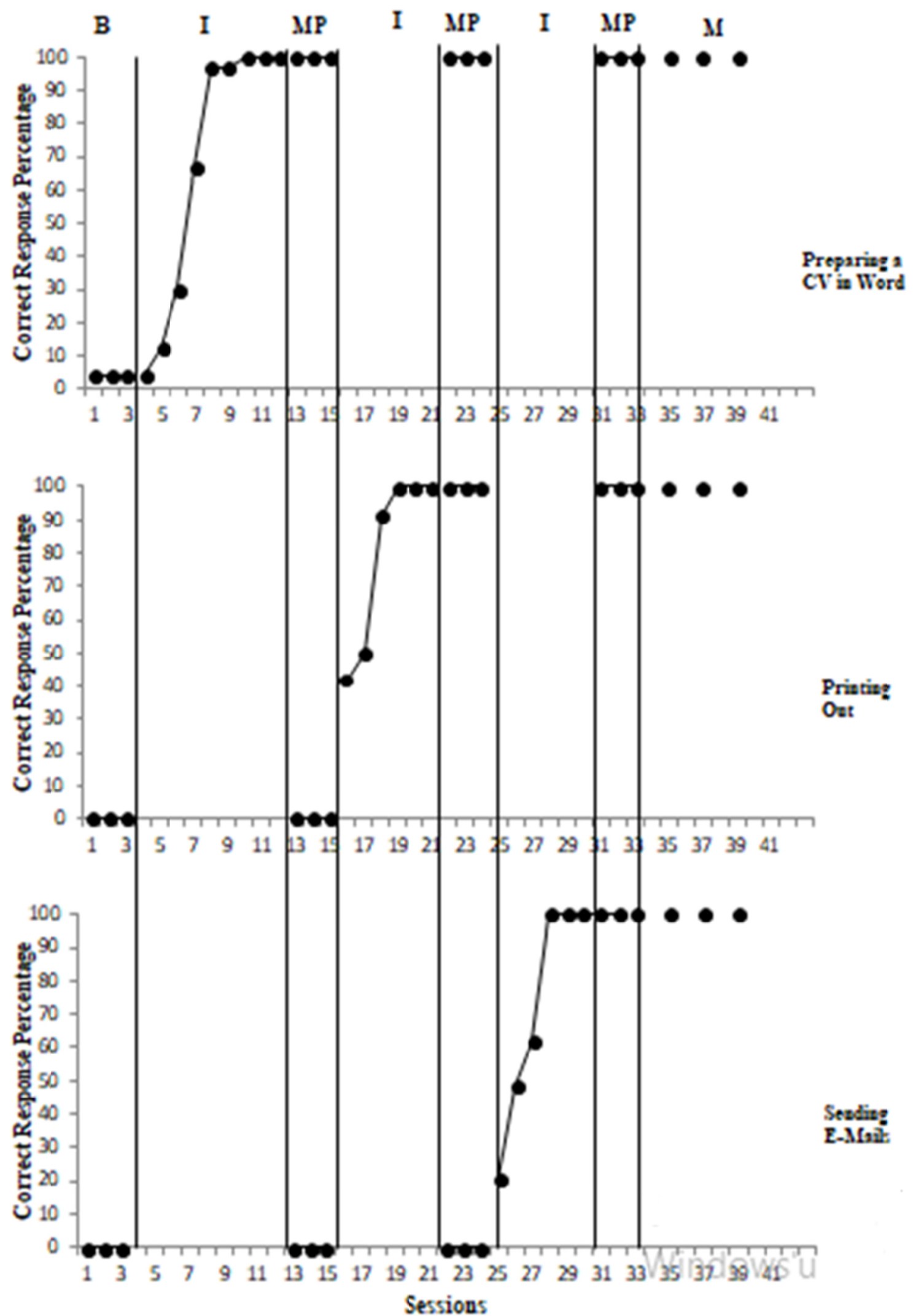

Figure 1. Gaye's correct response percentage for the baseline, intervention, multiple probe, and maintenance sessions

Note. B: Baseline; I: Intervention; M.P: Multiple Probe; M: Maintenance. 


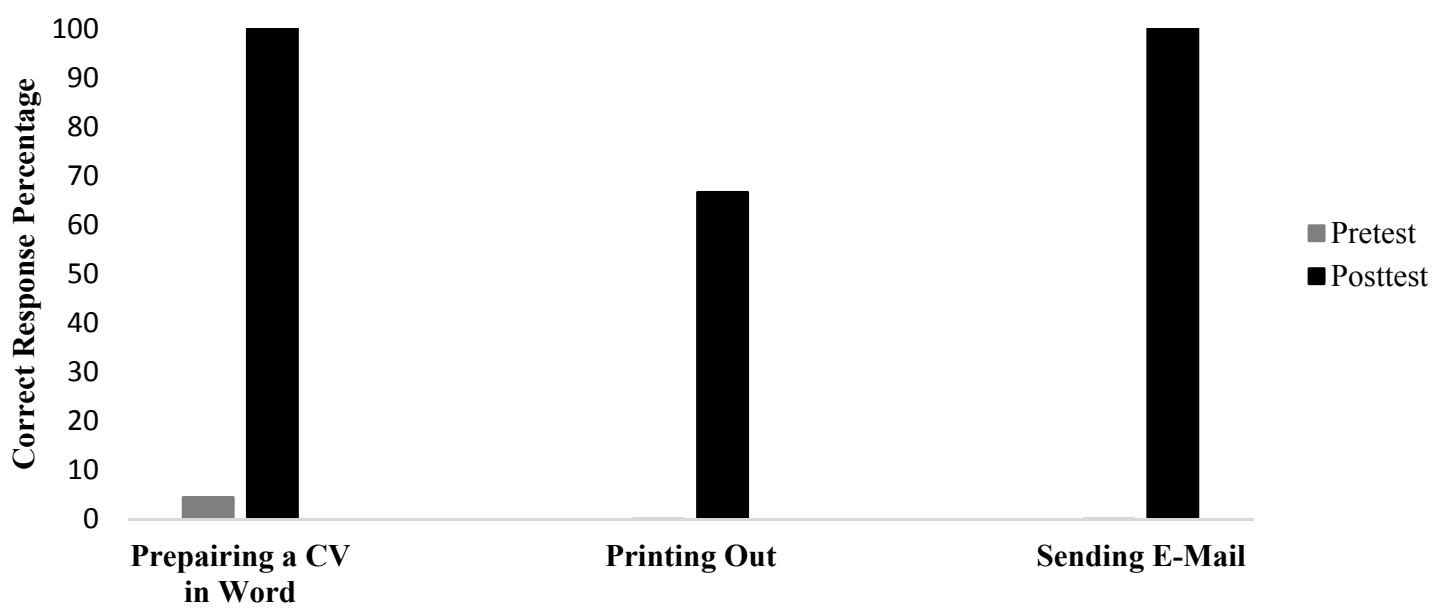

Figure 2. The pretest-posttest correct response percentage in Gaye's generalization session

Figure 3 shows Betül's baseline data at $0 \%$ of skills for preparing a résumé in Word. She completed all 66 skill steps independently at the end of ten sessions. For printing and emailing, Betül began with $0 \%$ skills but after seven and eight sessions, she completed these tasks independently. For preparing a résumé, she maintained $88 \%$ of the steps 12 days after the study and then $100 \%$ after 21 and 32 days. For printing and emailing, the level was $100 \%$. Figure 2 shows the results of Betül's generalization session. She generalized all steps for preparing a résumé and emailing across different settings, equipment, and people. However, she could not generalize preparing a résumé because a different brand of computer was used in the generalization session since the power button was in a different location. Betül only generalized $66 \%$ of the printing steps, because the printer was different. For emailing, she generalized $90 \%$ of the steps. In the generalization session, the Windows 10 system was used, which has the shutdown button in a different location. 


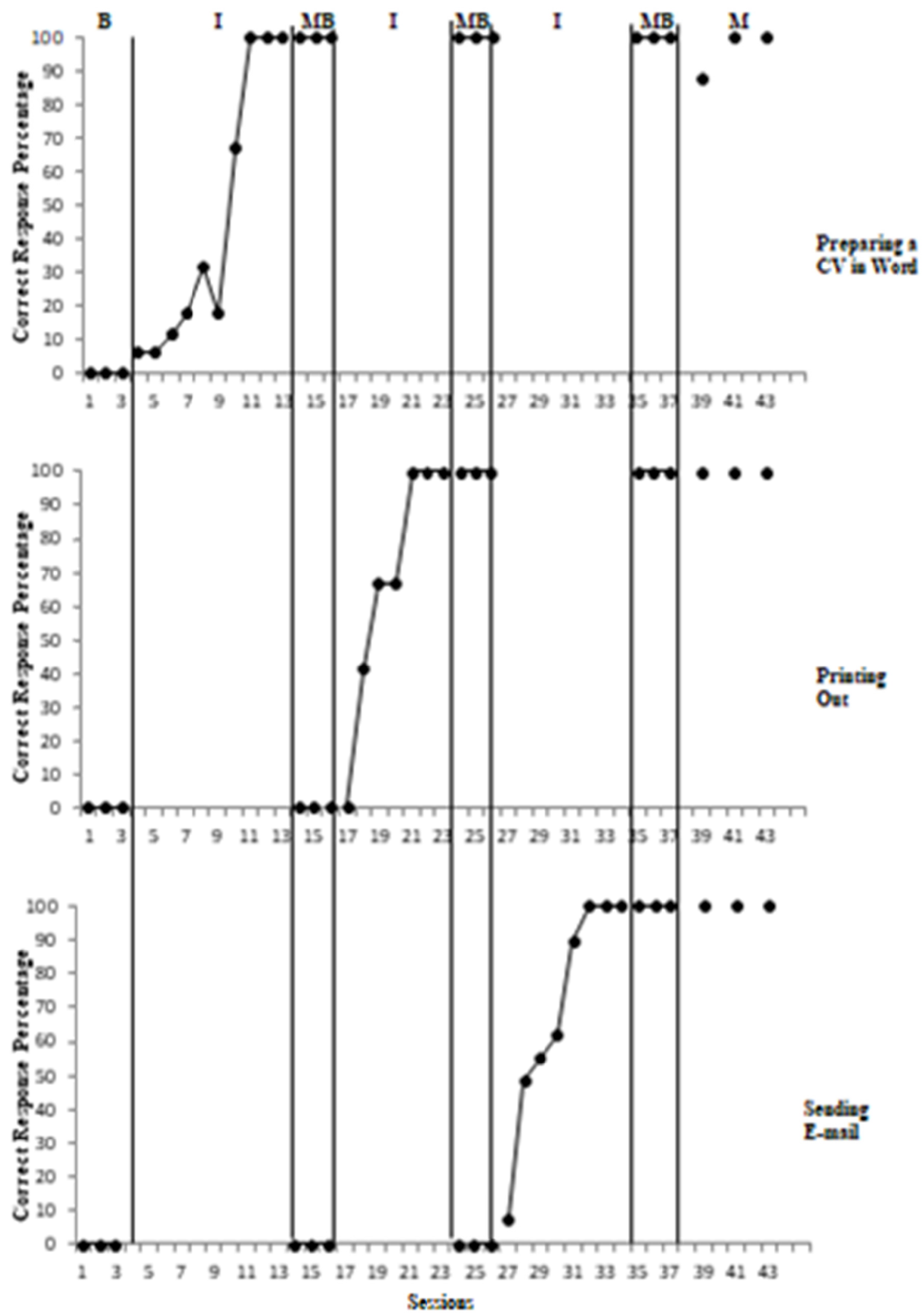

Figure 3. Betül's correct response percentage for the baseline, intervention, multiple probe, and maintenance sessions

Note. B: Baseline; I: Intervention; M.P: Multiple Probe; M: Maintenance. 


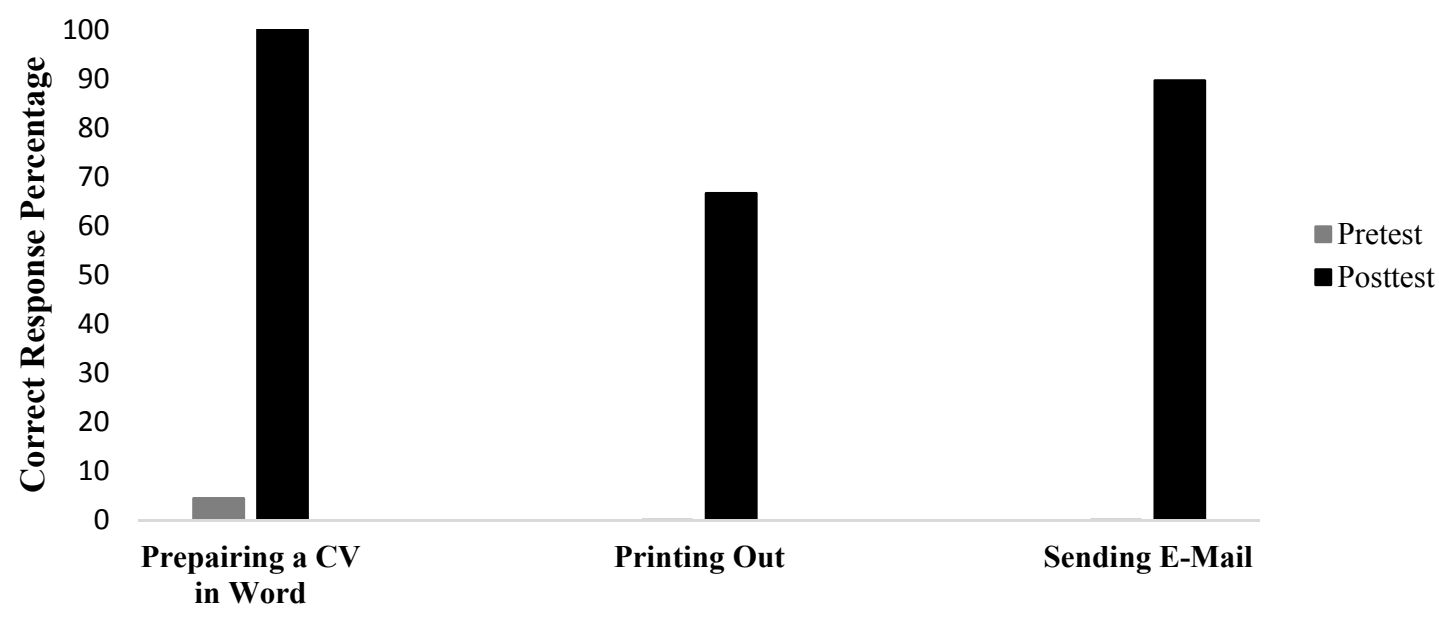

Figure 4. The pretest-posttest correct response percentage in Betül's generalization session

Figure 5 shows Sinem's baseline data at $4.5 \%$ for the steps in preparing a résumé in Word. She completed all 66 skill steps independently at the end of ten sessions. For printing and emailing, Sinem began with $0 \%$ of the skills but after seven sessions, she completed these tasks independently. She maintained all three of the skills she had acquired 12, 21, and 32 days after the study. Figure 2 shows results from Sinem's generalization session. She generalized all skills at $90 \%$ after the intervention. However, she only generalized $66 \%$ of the steps for printing, since when using a printer with a different a power button and paper drawer. For emailing, Sinem's skills improved from $0 \%$ to $89.6 \%$. It was not $100 \%$ because in the generalization session, the Windows 10 system was used, which has the shutdown button in a different location. 


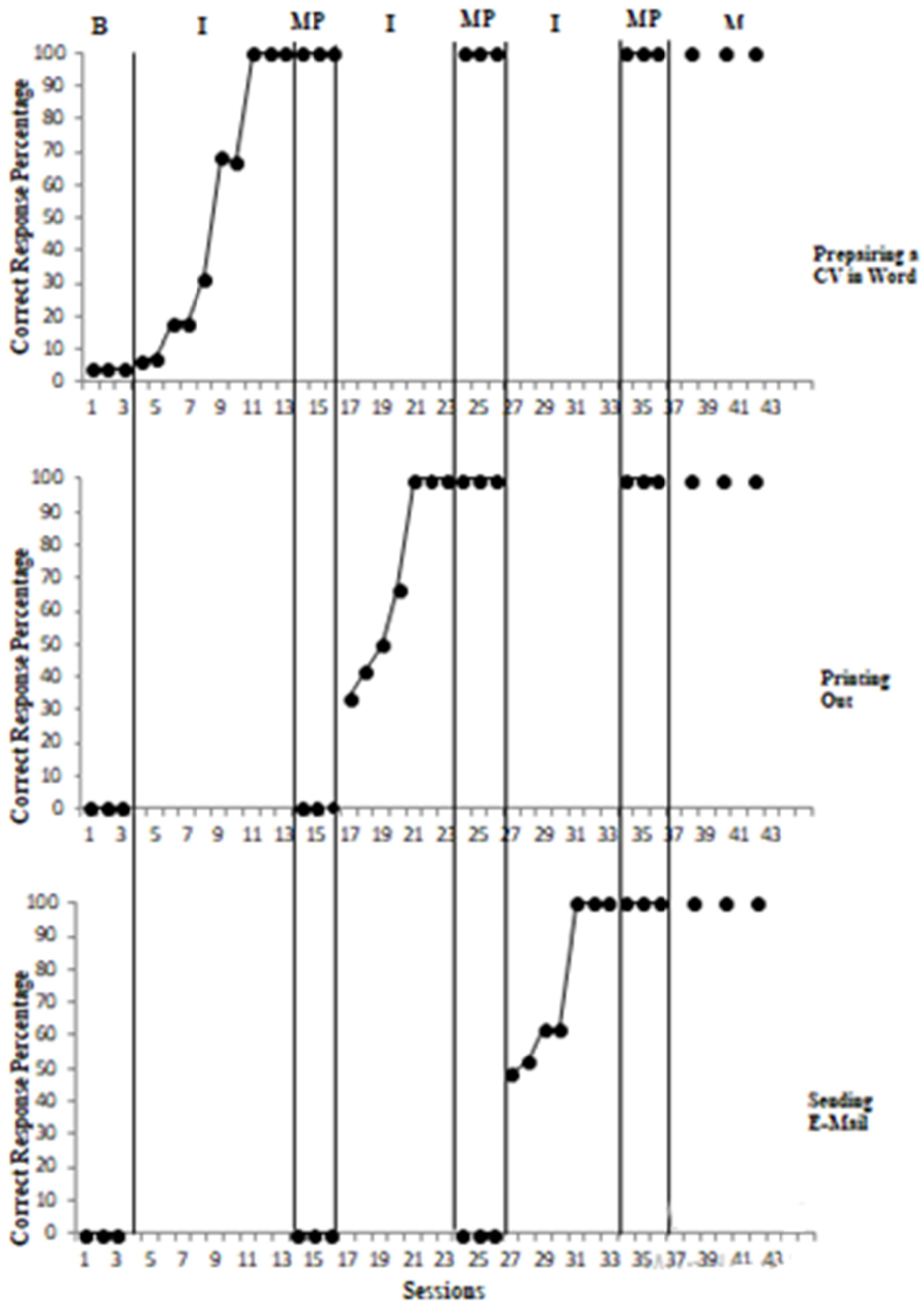

Figure 5. Sinem's correct response percentage for the baseline, intervention, multiple probe, and maintenance sessions

Note: B: Baseline; I: Intervention; M.P: Multiple Probe; M: Maintenance. 


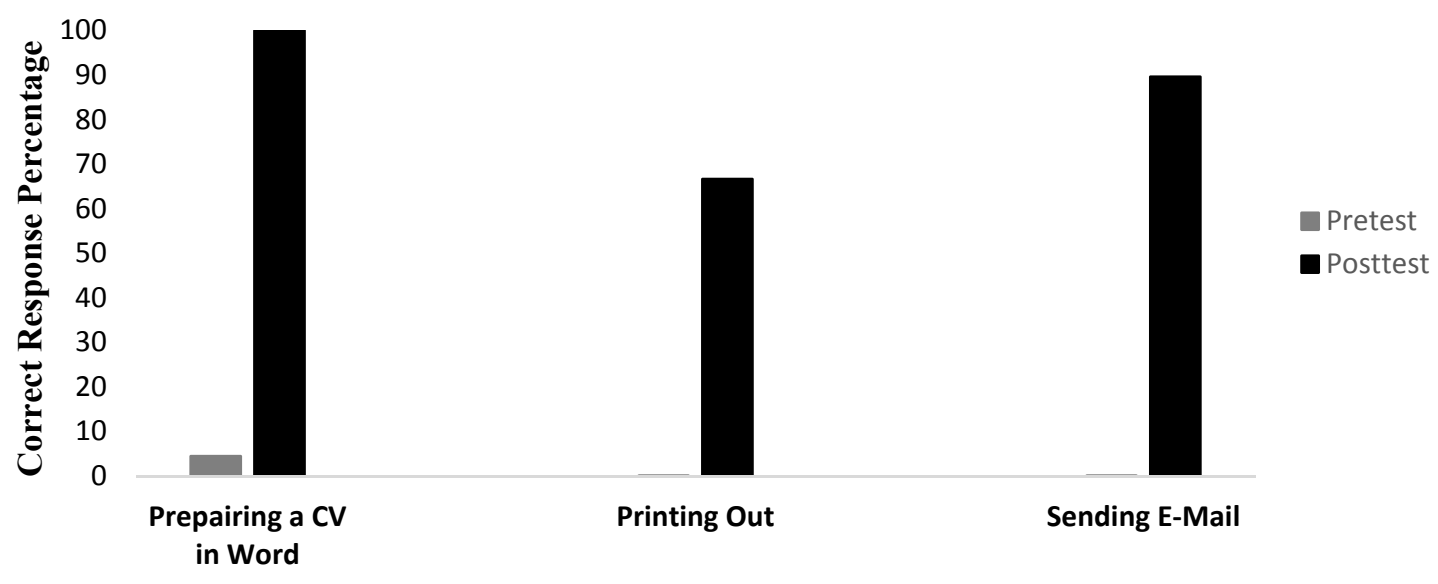

Figure 6. The pretest-posttest correct response percentage in Sinem's generalization session

Overall, the initial sessions shows that all participants started the study with essentially no computer skills. After the video teaching sessions, all participants performed and maintained all three skills. They were able to generalize these skills in different settings with different people, but were challenged by computers and printers with different designs. Generally, however, video modeling was effective in teaching computer skills.

The social validity data of the study were collected from the students, their families, and teachers. All three students were happy they had participated. They said they could use these skills while doing homework, applying for a job, communicating with friends, and when they had a job, at work. Families stated that they were satisfied with the skills and because their children were also happy, because it supported their children's development. One family stated that after their child learned to use a printer, she asked her father for one. Families indicated that they were satisfied with their children's use of technology but that they were afraid of misusing these skills or that their children would be deceived. Teachers said that the studies were beneficial for students to be better equipped and they supported more studies since they allowed students with intellectual disabilities to work independently, like their typically-developing peers. One teacher indicated that this study improved participants' self-confidence and ability to socialize. It also led to participants being more open and motivated.

\section{Discussion}

The use of computer technology is an inevitable part of modern life. Students with intellectual disabilities also need computer skills to have independent lives; especially since they are useful once they leave school and begin looking for a job. Employers usually look for computer skills (Baran \& Cavkaytar, 2007; Güneş, Akçamete, 2014; Lamb, 2003; Luecking, 2003; Ju et al., 2012).

Computer skills are an advantage for students with intellectual disabilities. The literature suggests these skills should be taught from an early age and continue until they graduate from high school (Burgstahler, 2003; Shicmizu \& McDonough 2006; Thompson, 2003; Wehmeyer et al., 2004). Learning these skills increases motivation, supports socialization, makes life easier, and increases job opportunities (Burgstahler, 2003; Jerome et al., 2007; Schimizu \& McDonough, 2006; Wehmeyer et al., 2004).

This study shows that video modeling is effective for teaching computer skills to students with intellectual disabilities. These skills have many steps; the success of this study suggests video modeling could be applied more broadly.

Some of the most important and useful computer skills are preparing a résumé in Word, printing, and sending e-mails, which are specifically needed to applying for a job after school. The use of these skills in office jobs makes these students more employable. We think that they should be implemented more broadly in education (Stodden et al., 2003).

Nowadays, teaching with video modeling is becoming very common for individuals with intellectual disabilities. The effectiveness of video modeling in teaching computer skills agrees with other similar studies (Edrishinha et al., 2011; Zisimipoulos et al., 2011). These students acquire the skills and show increased motivation (Ashton, 
2003; Sani-Bozkurt, 2017). Preparing video images makes it easier to see steps clearly.

In this study, students had difficulty generalizing skills to different equipment brands with different designs. Hence the results reinforce the suggestion that universal designs reduce accessibility barriers for people with intellectual disabilities (Braddock et al., 2004; Hitchcock \& Stahl, 2003; Jerome et al., 2007; Wehmeyer et al., 2004).

The social validity data indicate positive responses from the participants. They enjoyed learning by watching videos and when they made mistakes, they felt more comfortable than with a live person modeling the skill. The families of the participants noted improved self-confidence and supported additional programs. The teachers said they did not see any negative aspects but warned against the potential misuse of technology. This is the only study we are aware of on this topic that included social validity data.

One of the limitations of this study is that it was carried out with three female students with intellectual disabilities and only three skills were studied. Future studies could include people with different disabilities, methods, devices, and skills to verify the results presented here.

\section{Acknowledgments}

This research was undertaken in 2019 as part of the project TUBITAK-4006 (Scientific and Technological Research Council of Turkey).

\section{References}

Asthon, T. (2003). Assistive Technology. Journal of Special Education Technology, 18(2), 47-50. https://doi.org/10.1177/016264340301800407

Baran, N., \& Cavkaytar, A. (2007). Opinions and Suggestions of Employers on Employment of Individuals with Mental Retardation. Elementary Education Online, 6(2), 213-225. Retrieved from https://dergipark.org.tr/tr/pub/ilkonline/issue/8604/107169

Braddock, D., Rizzolo, M. C., Thompson, M., \& Bell, R. (2004). Emerging Technologies and Cognitive Disability. Journal of Special Education Technology, 18(4), 49-56. https://doi.org/10.1177/016264340401900406

Burgstahler, S. (2003). The Role Of Technology In Preparing Youth With Disabilities For Postsecondary Education And Employment. Journal of Special Education Technology, 18(4), 7-20. https://doi.org/10.1177/016264340301800401

Chiak, D. F., McMahon, D., Smith, C. C., Wright, R., \& Gibbons, M. M. (2015). Teaching İndividuals with İntellectual Disability to Email Across Multiple Device Platforms. Research in Developmental Disabilities, 36, 645-656. https://doi.org/10.1016/j.ridd.2014.10.044

Domianidou, D., Arthur-Kelley, M., Lyons, G., \& Wehmeyer, M. L. (2019). Technology use to support employment related outcomes for people with intellectual and developmental disability: An updated meta-analysis. International Journal of Developmental Disabilities, 65(4), 220-230. https://doi.org/10.1080/20473869.2018.1439819

Edrisinha, C., O’Reilly, M. F., Choi, H. Y., Sigafoos, J., \& Lancioni, G. E. (2011). "Say cheese": Teaching photography skills to adults with developmental disabilities. Research in Developmental Disabilities, 32, 636-642. https://doi.org/10.1016/j.ridd.2010.12.006

European Commission. (2010). European Disability Strategy 2010-2020. Retrieved from http://eur-lex.europa.eu/LexUriServ/LexUriServ.do?uri=COM\%3A2010\%3A0636\%3AFIN\%3A...

Güneş, N., \& Akçamete, G. (2014). Vocational Employment of Individuals with Special Needs the Case of Çorum. Ankara University Faculty of Educational Sciences Journal of Special Education, 15(3), 1-17. https://doi.org/10.1501/Ozlegt_0000000211

Hitchcock, C., \& Stahl, S. (2003). Assistive Technology, Universal Design, Universal Design for Learning: Improved Learning Opportunities. Journal of Special Education Technology, 18(4), 45-52. https://doi.org/10.1177/016264340301800404

Individuals with Disabilities Education Act. (1997). Public Law 105-17. Retrieved from http://www.ed.gov/offices/OSERS/Policy/IDEA/the_law.html

Jerome, J., Frantino, E. P., \& Sturmey, P. (2007). The effects of errorless learning and backward chaining on the acquisition of internet skills in adults with developmental disabilities. Journal of Applied Behavior Analysls, 
1(40), 185-189. https://doi.org/10.1901/jaba.2007.41-06

Ju, S., Zhang, D., \& Pacha, J. (2012). Employability skills valued by employers as important for entry-level employees with and without disabilities. Career Development for Exceptional Individuals, 35, 29-38. https://doi.org/10.1177/0885728811419167

Kagohara, D. M. (2011). Three students with developmental disabilities learn to operate an ipod to Access age-appropriate entertainment videos. Journal of Behavioral Education, 20, 33-43. https://doi.org/10.1007/s10864-010-9115-4

Kellems, R. O., \& Morninsgstar, M. E. (2012). Using video modeling delivered through iPods to teach vocational tasks to young adults with autism spectrum disorders. Career Development and Transition for Exceptional Individuals, 35(3), 155-167. https://doi.org/10.1177/2165143412443082

Lamb, P. (2003). The Role of the Vocational Rehabilitation Counselor in Procuring Technology to Facilitate Success in Postsecondary Education for Youth with Disabilities. Journal of Special Education Technology, 18(4), 53-62. https://doi.org/10.1177/016264340301800405

Luecking, R. G. (2003). Employer Perspectives on Hiring and Accommodating Youth in Transition. Journal of Special Education Technology, 18(4), 65-72. https://doi.org/10.1177/016264340301800406

Sani-Bozkurt, S. (2017). Digital Support in Special Education: Assistive Technologies. Journal of Open Education Applications and Research, 3(2), 37-60. Retrieved from https://dergipark.org.tr/tr/pub/auad/issue/34117/378439

Shih, C. H. (2013). Assisting people with disabilities improves their collaborative pointing efficiency through the use of the mouse scroll wheel. Research in Developmental Disabilities, 34, 1-10. https://doi.org/10.1016/j.ridd.2012.07.016

Shih, C. H., Chang, M. L., \& Shih, C. T. (2009). Assisting people with multiple disabilities and minimal motor behavior to improve computer pointing efficiency through a mouse wheel. Research in Developmental Disabilities, 30, 1378-1387. https://doi.org/10.1016/j.ridd.2009.06.005

Shih, C.-H., Chiu, S. K., Chu, C. L., Shih, C. T., Liao, Y. K., \& Lin, C. C. (2010). Assisting people with multiple disabilities improve their computer-pointing efficiency with hand swing through a standard mouse. Research in Developmental Disabilities, 31, 517-524. https://doi.org/10.1016/j.ridd.2009.12.005

Shih, C. H., Li, C. C., Shih, C. T., Lin, K. T., \& Lo, C. S. (2010). Extended Automatic Pointing Assistive Program a pointing assistance program to help people with developmental disabilities improve their pointing efficiency. Research in Developmental Disabilities, 31, 672-679. https://doi.org/10.1016/j.ridd.2010.01.006

Sigafoos, J., O'Reilly, M., Cannella, H., Upadhyaya, M., Edrisinha, C., Lancioni, G. E., ... Young, D. (2005). Computer-presented video prompting for teaching microwave oven use to three adults with developmental disabilities. Journal of Behavioral Education, 3(14), 189-201. https://doi.org/10.1007/s10864-005-6297-2

Stodden, R. A., Conway, M. A., \& Chang, K. B. T. (2003). Findings from the Study of Transition, Technology and Postsecondary Supports for Youth with Disabilities: Implications for Secondary School Educators. Journal of Special Education Technology, 18(4), 29-44. https://doi.org/10.1177/016264340301800403

Tekin-İftar, E., \& Kurcaali-İftar, G. (2013). Error-free teaching methods in special education (3rd ed.). Ankara: Vize Publishing.

Thompson, T. (2003). The Interdependent Roles of All Players in Making Technology Accessible. Journal of Special Education Technology, 18(4), 21-28. https://doi.org/10.1177/016264340301800401

Wehmeyer, L. M., Smith, J. S., Palmer, B. S., \& Davies, K. D. (2004). Technology use by students with intellectual disabilities: An overwiew. Journal of Special Education Technology, 19(4), 7-22. https://doi.org/10.1177/016264340301800401

Zirpoli, T. J., \& Melloy, K. J. (1997). Behavior management: Applications for teachers and parents (2nd ed.). Upper Saddle River, NJ: Merril.

Zisimopoulos, D., Sigafoos, J., \& Koutromanos, G. (2011). Using video prompting and constant time delay to teach an internet search basic skill to students with intellectual disabilities. Education and Training in Autism and Developmental Disabilities, 46(2), 238-250. Retrieved from https://www.jstor.org/stable/23879694 


\section{Copyrights}

Copyright for this article is retained by the author, with first publication rights granted to the journal.

This is an open-access article distributed under the terms and conditions of the Creative Commons Attribution license (http://creativecommons.org/licenses/by/4.0/). 